\title{
Fabrication of Micro Annular Grooves on a Cylindrical Surface in Aluminum Alloys by Wire Electrochemical Micromachining
}

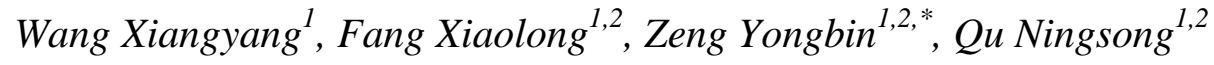 \\ ${ }^{1}$ College of Mechanical and Electrical Engineering, Nanjing University of Aeronautics and \\ Astronautics, Nanjing, 210016, China \\ 2 Jiangsu Key Laboratory of Precision and Micro-Manufacturing Technology, Nanjing, 210016, China \\ *E-mail: binyz@nuaa.edu.cn
}

doi: $10.20964 / 2016.08 .62$

Received: 16 May 2016 / Accepted: 15 June 2016 / Published: 7 July 2016

\begin{abstract}
Micro grooves, as a prominent microstructure in micro instruments, have been well applied in various industrial advanced applications. This study addressed to wire electrochemical micromachining (WECMM) of micro annular grooves on a cylindrical surface in an aluminum rod. By employing neutral electrolyte of sodium nitrate solution, the process would inevitably generate passive film on the surface at low current density. Thus, the dissolution characteristics of aluminum were experimentally analyzed by polarization curve. Under the optimized parameters, arrayed micro annular grooves with width of $100 \mu \mathrm{m}$, pitch of $80 \mu \mathrm{m}$ and depth of $100 \mu \mathrm{m}$ were fabricated on an aluminum rod with a diameter of $3 \mathrm{~mm}$. This study revealed that WECMM is a promising method to produce micro annular grooves on a cylindrical surface in aluminum alloys.
\end{abstract}

Keywords: wire electrochemical micromachining, aluminum alloy, dissolution characteristic, micro annular grooves

\section{FULLTEXT}

(C) 2016 The Authors. Published by ESG (www.electrochemsci.org). This article is an open access article distributed under the terms and conditions of the Creative Commons Attribution license (http://creativecommons.org/licenses/by/4.0/). 